\title{
Pengawasan Proses Pembelajaran Sosiologi di SMA Negeri 9 Solok Selatan
}

\author{
Sri Gusma Nengsih ${ }^{1}$, Desri Nora $A N^{2}$ \\ ${ }^{1,2}$ Universitas Negeri Padang \\ Email: srigusmanengsih137@gmail.com, desrinora@ymail.com
}

\begin{abstract}
Abstrak
Penelitian ini dilatar belakangi kegiatan pengawasan proses pembelajaran sosiologi di SMA Negeri 9 Solok Selatan belum berjalan secara optimal. Karena pengawas jarang melakukan kunjungan ke SMA Negeri 9 Solok Selatan karena kondisi jalan yang ditempuh juga tidak memungkinkan dan juga jalan yang ditempuh oleh pengawas pun jauh untuk menuju sekolah tersebut. Salah satu faktor yang dapat mengoptimalkan pengawasan proses pembelajaran dengan melakukan kunjungan pengawas ke SMA Negeri 9 Solok Selatan. Maka untuk melihat bagaimana pengawasan proses pembelajaran sosiologi di SMA Negeri 9 Solok Selatan. Artikel ini bertujuan untuk mengetahui bagaimana kegiatan supervisi pendidikan yang dilakukan oleh pengawas dan kepala sekolah dalam meningkatkan kinerja guru mata pelajaran sosiologi di SMA Negeri 9 Solok Selatan. Metode penelitian yang digunakan adalah kualitatif dengan tipe studi kasus. Teknik pengumpulan data yang digunakan adalah observasi, wawancara dan studi dokumentasi. Hasil penelitian ini menunjukan bahwa Pengawas dan kepala sekolah dalam melaksankan supervisi sudah sesuai dengan perumusan program bersama, seperti pengembangan sumber daya guru, dan membimbing untuk perbaikan pengajaran terhadap guru-guru.
\end{abstract}

Kata kunci: Pengawasan, Proses pembelajaran, Sosiologi

\begin{abstract}
This research was motivated by the activity of monitoring the sociology learning process at SMA Negeri 9 Solok Selatan which had not been running optimally. Because supervisors rarely make visits to SMA Negeri 9 Solok Selatan because the road conditions are not possible and the roads taken by the supervisors are also far to get to the school. One of the factors that can optimize the supervision of the learning process is by visiting supervisors at SMA Negeri 9 Solok Selatan. So to see how the supervision of the sociology learning process at SMA Negeri 9 Solok Selatan. This article aims to find out how the educational supervision activities carried out by school supervisors and principals in improving the performance of sociology subject teachers at SMA Negeri 9 Solok Selatan. The research method used is qualitative with case study type. The data collection techniques used were observation, interview and documentation study. The results of this study indicate that supervisors and principals in carrying out supervision are in accordance with the formulation of joint programs, such as developing teacher resources, and guiding the improvement of teaching for teachers
\end{abstract}

Keywords: Supervision, The learning process, Sociology

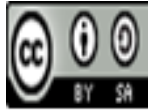

Received: October 15, 2020 Revised: November 11, 2020 Accepted: November 15, 2020 


\section{Pendahuluan}

Pendidikan adalah suatu usaha sadar dan terencana untuk mewujudkan suasana belajar dan proses pembelajaran agar siswa dapat aktif mengembangkan potensinya (Firmansyah, 2020). Pendidikan bukan suatu produk yang langsung jadi, tapi pendidikan merupakan suatu proses dan layanan. Proses dan layanan akan berjalan baik bila semuanya sepakat, bahwa pendidikan harus dibangun sejalan antara pembangunan fisik dan ketersediaan tenaga pendidik dan kependidikan yang bermutu sehingga mampu mendukung proses layanan pendidikan sesuai dengan apa yang diharapkan (Mayang, 2020).

Pengawasan merupakan suatu proses kegiatan yang terdiri dari kontrol, inspeksi dan supervisi pembinaan. Kontrol bertujuan untuk memeriksa apakah pekerjaan berjalan seperti yang telah direncanakan. untuk mengetahui bagaimana proses pekerjaan dilakukan Supervisi merupakan pembinaan, bertujuan untuk memperbaiki dan meningkatkan mutu pekerjaan(Suhardan,2007).

Menurut Johnson pengawasan proses pembelajaran adalah sebagai fungsi sistem yang melakukan penyesuaian terhadap rencana, mengusahakan agar penyimpangan -penyimpangan tujuan sistem hanya dalam batas-batas yang dapat ditoleransi. Dengan demikian dapat ditegaskan bahwa sasaran pengawasan adalah perilaku indivisu sebagai orang-orang yang memproses lancarnya kegiatan pembelajaran dan tidak terjadinya penyimpangan (Sagala, 2011).

Robbins menyatakan pengawasan adalah proses monitor aktivitas-aktivitas untuk mengetahui apakah individu-individu dan organisasi itu sendiri memperoleh dan memanfaatkan sumber-sumber secara efektifdan efisien dalam mencapai tujuan.

Supervisi merupakan hal yang tidak dapat dihilangkan dalam pendidikan, karena termasuk dalam evaluasi pendidikan. Supervisi merupakan usaha memberi layanan kepada guru-guru baik secara individual maupun secara kelompok dalam usaha memperbaiki pembelajaran. Pengertian tersebut mengkhususkan kepada supervisi akademik karena menitik beratkan pada masalah akademik yang berkaitan dengan masalah pembelajaran. Supervisi akademik digunakan sebagai bantuan dalam pemecahan masalah dan pengembangan guru. Dengan adanya supervisi akademik, guru seharusnya merasa terbantu karena masalahnya terselesaikan dan dapat mengembangkandiri.

Pengawasan atau supervisi merupakan aktivitas penting dalam praktek penyelenggaraan pendidikan (Purwanto,2014). Tujuan supervisi bukan hanya memperbaiki kemampuan mengajar tapi juga untuk pengembangan potensi kualitas guru(Nurindarwati, 2020). Tujuan supervisi untuk membantu guru-guru melihat dengan jelas tujuan pendidikan dan berusaha mencapai tujuan pendidikan dengan mengembangkan metode-metode pengajaran yang lebih baik (Marismania, 2020). Untuk melakukan supervisi akademik secara efektif diperlukan keterampilan konseptual, interpersonal dan teknikal. Kepala sekolah harus memiliki dan menguasai konsep supervisi akademik yang meliputi pengertian, tujuan, fungsi, prinsip, dan dimensi subtansi supervisi akademik (Yunathan, 2020). Dengan supervisi diharapkan guru memiliki kemampuan dan dapat meningkatkan proses dan hasil pembelajaran yang berkualitas (Ansori, 2016). Artikel ini akan menggambarkan mengenai hasil penelitian terhadap proses pengawasan pembelajaran sosiologi di SMAN 9 Solok Selatan pada rentang waktu JuliDesember 2020. Penelitian ini dianalisis menggunakan teori Struktural Fungsional oleh Talcott Parson dengan skema AGIL.

\section{Metode Penelitian}

Penelitian ini berjenis penelitian kualitatif (Sukmadinata \& Nana Syaodih, 2007). Penelitian ini bertujuan untuk mendeskripsikan tentang pengawasan proses pembelajaran sosiologi di SMA Negeri 9 Solok Selatan. Penelitian kualitatif adalah penelitian yang ditujukan untuk mendeskripsikan dan menganalisis fenomena, peristiwa, aktivitas sosial, sikap, 
kepercayaan, persepsi, pemikiran orang secara individu maupun kelompok (Sukmadinata \& Nana Syaodih, 2007). Penelitian ini dilakukan di SMA Negeri 9 Solok Selatan. Alasan penelitian ini dilakukan di SMA Negeri 9 Solok Selatan karena sekolah tersebut jauh dari tempat keramaian jadi menarik jika peneliti melakukan penelitian di sana. Pemilihan informan dalam penelitian ini dilakukan melalui teknik purposive sampling. Teknik purposive sampling sangat cocok untuk meneliti penelitian kualitatif. Teknik purposive sampling adalah teknik penentuan sampel dengan pertimbangan tertentu, untuk menentukan siapa yang akan menjadi informan sesuai dengan data yang diinginkan (Sugiyono, 2006). Dengan informan penelitian pengawas sekolah, kepala sekolah, wakil kurikulum dan guru mata pelajara sosiologi. Teknik pengumpulan data melalui observasi, wawancara dan dokumentasi. Peneliti melakukan wawancara kepada informan untuk mengetahui tentang pengawasan proses pembelajaran sosiologi di SMA Negeri 9 Solok Selatan. Peneliti mengumpulkan data yang digunakan untuk memperoleh informasi secara lisan melalui wawancara tatap muka dengan informan. Kemudian studi dokumentasi dilakukan untuk melengkapi data hasil obsevasi dan wawancara. Analisis data dilakukan dengan empat jalur kegiatan yang terjadi secara bersama, yaitu pengumpulan data, Reduksi data, penyajian data, verifikasi/menarik kesimpulan (Sugiyono, 2017).

\section{Hasil dan Pembahasan}

\section{Hasil dari Pengawasan Proses Pembelajaran}

Pelaksanaan pengawasan proses pembelajaran sosiologi di SMA Negeri 9 Solok dilakukan dengan: melakukan pertemuan awal dengan kepala sekolah dan guru-guru serta staf administrasi sekolah karena dengan pertemuan tersebut pengawas bersama kepala sekolah guru-guru dan staf administrasi melakukan kesepakatan untuk bekerjasama melaksanakan supervisi. Di samping itu, pengawas harus minta izin terlebih dahulu kepada kepala sekolah untuk melakukan supervisi; pengawas saling bekerjasama dalam membina guru-guru tanpa memandang senioritas atau mana pengawas yang lebih baik; selanjutnya pengawas menyusun dan menyiapkan insturmen. Sesuai dengan tugas pokok pengawas yaitu: pertama, melaksanakan pengawasan penyelenggaraan pendidikan di sekolah sesuai dengan satuan pendidikan, Kedua, meningkatkan kualitas proses belajar mengajar atau hasil prestasi belajar siswa dalam rangka mencapai tujuan pendidikan. Seorang Pengawas, dalam melakukan kunjungan ke sekolah yang terkait dengan supervisi yakni meliputi: kurikulum mata pelajaran, kegiatan belajar mengajar, proses belajar mengajar, silabus/RPP dan memberikan arahan kepada Kepala sekolah serta guru untuk lebih baik dalam menyampaikan materi di kelas, sehingga guru-guru yang akan mengajarkan pahan dengan apa yang ada di RPP sama yang disampaikan dikelas nantinya. Diketahui bahwa yang dilakukan pengawas saat melakukan kunjungan ke sekolah benar-benar memberikan arahan dan pembinaan terhadap SDM di sekolah tersebut, baik terhadap kepada Kepala sekolah maupun kepada guru, mulai dari perencanaan kurikulum, proses belajar mengajar dan silabus/RPP. Dengan demikian dapat dilihat bagaimana kinerja guru di SMA Negeri 9 Solok Selatan.Setelah melakukan kunjungan, pengawas memberikan bimbingan dalam kegiatan belajar mengajar di SMA Negeri 9 Solok Selatan sesuai dengan jadwal kunjungan.

\section{Fungsi dan Tujuan Supervisi Pendidikan}

Fungsi supervisi merupakan suatu kegiatan tetap yang sejenis (mengenal, memantau, mengarahkan, menilai dan melaporkan) dalam suatu organisasi yang menjadi tanggung jawab seseorang/badan. Dan bila dipandang sebagai sesuatu yang ingin dicapai supervisi, maka hal itu merupakan tujuan dari supervisi. Maka fungsi dan tujuan supervisi sangat berhubungan erat, dan keduanya menyangkut hal yang sama. Hal ini dibedakan agar informasi yang diberikan nanti menjadi lebih lengkap. Fungsi supervisi dapat dibedakan menjadi dua bagian besar antara lain: a). Fungsi utama ialah membantu sekolah yang sekaligus mewakili pemerintah dalam usaha mencapai tujuan pendidikan yaitu membantu mengembangkan potensi individu peserta

Jurnal Sikola: Jurnal Kajian Pendidikan dan Pembelajaran Vol. 2, No. 2, Th. 2020 
didik. b). Fungsi tambahan ialah membantu sekolah dalam membina para guru dan staf personalia agar ingin bekerja dan mengajar dengan baik dan dalam mengadakan kontak dengan masyarakat dalam rangka menyesuaikan diri dengan tuntutan masyarakat serta mempelopori kemajuan masyarakat sekitar.

\section{Tanggung Jawab dan Wewenang Pengawas}

Secara rinci, tanggung jawab pengawas pada satuan pendidikan menengah dijelaskan sebagaimana berikut: a). Melakukan pengawasan terhadap pelaksanaaan tugas guru dari SMP, SMA/SMK dan SLB dan guru serta tenaga lainya. b). Melakukan pengawasan terhadap pelaksanaan kinerja guru di SMP, SMA/SMK dan pnyelenggara sekolah lainnya. Adapun wewenang yang diberikan kepada pengawas meliputi: a.Memilih dan menentukan metode kerja untuk mencapai hasil yang optimal dalam melaksanakan tugas dengan sebaik-baiknya sesuai dengan kode etik profesi, b.Menetapkan tingkat kinerja guru dan tenaga lainnya yang diawasi beserta faktor-faktor yang mempengaruhinya, c.Menentukan atau mengusulkan program pembinaan serta melakukan pembinaan kepada kepala sekolah, dan atau pejabat struktural pembina sekolah yang bersangkutan, d.Melakukan penilaian terhadap pelaksanaan kegiatan supervisi yang meliputi keterbacaan dan keterlaksanaan program supervisi, keterbacaan dan kemantapan instrument, hasil supervisi, kendala, dan tindak lanjutnya. Wewenang tersebut menyiratkan adanya otonomi pengawas untuk menentukan langkah dan strategi dalam menentukan prosedur kerja kepengawasan. Namun demikian pengawas perlu berkolaborasi dengan kepala sekolah dan guru agar dalam melaksanakan tugasnya sejalan dengan arah pengembangan sekolah yang telah ditetapkan kepala sekolah.

\section{Kedudukan dan Tugas Pokok Pengawasan}

Tugas pokok pengawas sekolah/satuan pendidikan adalah melakukan penilaian dan pembinaan dengan melaksanakan fungsi-fungsi supervisi, baik supervisi akademik maupun supervisi manajerial. Berdasarkan tugas pokok dan fungsi di atas minimal ada tiga kegiatan yang harus dilaksanakan pengawas yakni: a). Melakukan pembinaan dan pengembangan sekolah, kinerja kepala sekolah, kinerja guru dan seluruh staf sekolah. b). Melakukan evaluasi dan monitoring pelaksanaan program sekolah serta pengembanganya. c). Melaksanaan penilaian terhadap proses dan hasil program pengembangan sekolah secara kolaboratif dengan stake holder sekolah.

Bedasarkan penelitian yang peneliti lakukan pada tanggal Juli-Desember 2020 di SMA Negeri 9 Solok Selatan tentang Pengawasan Proses Pembelajaran Sosiologi, diperoleh hasil proses pengawasan pembelajaran yang dilakukan adalah dengan adanya pemantauan pada proses pembelajaran yang dilakukan pada tahap perencanaan, pelaksanaan, dan penilaian dari hasil pembelajaran. Pemantauan ini dilakukan dengan diskusi kelompok, pengamatan, pencatatan, perekaman,wawancara dan dokumentasi. Tahap selanjutnya adalah dengan melakukan supervisi, yang dilakukan pada tahap perencanaan, pelaksanaan, dan penilaian dari hasil pembelajaran dikelas, diskusi,konsultasi atau pelatihan. Tahapan selanjutnya dengan adanya pelaporan hasil dari pemantauan, supervisi, dan evaluasi proses pembelajaran disusun dalam bentuk laporan untuk kepentingan tindak lanjut pengembangan keprofesionalan pendidik secara berkelanjutan. Tahap terakhir adalah dengan adanya tindak lanjut dimana tindak lanjutan dari pengawasan dilakukan dalam bentuk penguatan dan penghargaan kepada guru yang menunjukkan kinerja yang memenuhi atau melampaui standar dan dengan pemberian kesempatan kepada guru untuk mengikuti program pengembangan keprofesionalan berkelanjutan.

Evaluasi supervisi Pendidikan adalah suatu proses menentukan tingkat keberhasilan supervisi akademik dengan menggunakan patokan-patokan tertentu guna mencapai tujuan pendidikan yang telah ditentukan sebelumnya (Syahrudin, Sulton Djasmi, n.d.). Berdasarkan

Jurnal Sikola: Jurnal Kajian Pendidikan dan Pembelajaran Vol. 2, No. 2, Th. 2020 
uraian tugas-tugas pengawas sebagaimana dikemukakan di atas, maka pengawas satuan pendidikan banyak berperan sebagai: penilai, peneliti, pengembang, pelopor/inovator, motivator, konsultan, dan kolaborator dalam rangka meningkatkan mutu pendidikan di sekolah binaannya.

\section{Tugas Pengawas}

1). Membantu guru agar dapat memahami lebih jelas masalah ataupersoalan-persoalan dan kebutuhan murid serta membantu gurudalam mengatasi suatu persolan 2). Membantu guru dalam kesukaran mengajar 3). Memberikan bimbingan yang bijaksana terhadap guru danorientasi 4). Membantu guru memperoleh kecakapan mengajar yang lebihbaik dengan menggunakan berbagai metode mengajar sesuaidengan sifat materinya 5). Membantu guru memperkaya pengalaman mengajar, sehinggasuasana pengajaran bisa menggerakan anak didik 6). Membina moral kelompok, menumbuhkan moral yang tinggidalam pelaksanaankemampuan dalam pelaksanaan tugas 7). Memberikan pimpinan yang efektif dan demokratis (Sumidjo, 2008)

Pengawasan proses pembelajaran sebagaimana telah diformulasikan dalam peraturan menteri pendidikan dan kebudayaan nomor 22 tahun 2016 tentang standar proses pendidikan dasar dan menengah. Pengawasan proses pembelajaran dilakukan melalui kegiatan pemantauan, supervisi, evaluasi, pelaporan, serta tindak lanjut secara berkala dan berkelanjutan. Pengawasan proses pembelajaran dilakukan oleh kepala satuan pendidikan dan pengawas. 1) Prinsip Pengawasan Prinsip pengawasan dilakukan dengan prinsip objektif dan transparan guna peningkatan mutu secara berkelanjutan. 2). Sistem dan Entitas Pengawasan. Sistem pengawasan internal dilakukan oleh kepala sekolah, pengawas, dan dinas pendidikan dan Lembaga Penjaminan Mutu Pendidikan. a). Kepala Sekolah, Pengawas dan lembaga penjaminan mutu pendidikan melakukan pengawasan dalam rangka peningkatan mutu. b). Kepala Sekolah dan pengawas melakukan pengawasan dalam bentuk supervisi akademik dan supervisi manajerial. 3) Proses Pengawasan a) Pemantauan, Pemantauan proses pembelajaran dilakukan pada tahap perencanaan, pelaksanaan, dan penilaian hasil pembelajaran. Pemantauan dilakukan melalui antara lain, diskusi kelompok terfokus, pengamatan, pencatatan, perekaman, wawancara, dan dokumentasi. b). Supervisi, Supervisi proses pembelajaran dilakukan pada tahap perencanaan, pelaksanaan, dan penilaian hasil pembelajaran yang dilakukan melalui antara lain, pemberian contoh pembelajaran di kelas, diskusi, konsultasi, atau pelatihan. 4). Pelaporan, Hasil kegiatan pemantauan, supervisi, dan evaluasi proses pembelajaran disusun dalam bentuk laporan untuk kepentingan tindak lanjut pengembangan keprofesionalan pendidik secara berkelanjutan. a). Tindak Lanjut, Tindak lanjut hasil pengawasan dilakukan dalam bentuk: Penguatan dan penghargaan kepada guru yang menunjukkan kinerja yang memenuhi atau melampaui standar. Dan Pemberian kesempatan kepada guru untuk mengikuti program pengembangan keprofesionalan berkelanjutan.

Teori yang di pakai dalam penelitian ini adalah Struktural Fungsional oleh Talcot Parson (Upe, 2010). Aliran ini berasumsi dasar bahwa masyarakat merupakan suatu sistem yang terdiri dari bagian-bagian yang saling berkaitan dan berfungsi dengan bagian-bagian yang lainnya. Apabila bagian tidak berfungsi dengan baik maka akan mempengaruhi sistem yang lainnya (Upe, 2010)

\section{Kesimpulan}

Berdasarkan penelitian yang telah penulis lakukan di SMA Negeri 9 Solok Selatan penulis memperoleh kesimpulan sebagai berikut: 1).Pelaksanaan supervisi oleh Pengawas dan Kepala sekolah yaitu dengan merumuskan program tahunan terhadap kinerja guru dalam hal melaksanakan proses belajar mengajar, ketrampilan guru menggunakan media, persiapan mengajar (silabus dan RPP), menyusun waktu penjadwalan pembinaan dan pelayanan kemampuan mengajar guru dilakukan 1 kali sebulan dilakukan pengawas dan kepala sekolah..

Jurnal Sikola: Jurnal Kajian Pendidikan dan Pembelajaran Vol. 2, No. 2, Th. 2020 
Kemudian menyusun hasil analisis evaluasi kedalam format program kegiatan supervisi yang telah ditentukan. Dalam menyusun program pihak Pengawas dan Kepala sekolah telah berkoordinasi dalam mengikuti langkah-langkah sebagai berikut: 1) Mengidentifikasi alternatif cara memenuhi kebutuhan guru. 2) Mengatasi kendala. 3) Melakukan evaluasi. 2). Pelaksanaan supervisi akademik oleh Pengawas dan Kepala sekolah di SMA Negeri 9 Solok Selatan dilakukan dengan cara individu, observasi kelas, kunjungan kelas, bersifat kelompok, rapat supervisi, pelatihan guru. Pada setiap kegiatan supervisi oleh Pengawas dan Kepala sekolah didukung oleh bukti fisik. Koordinasi berjalan dengan baik karena adanya informasi, komunikasi dan pemahaman yang sama. 3). Supervisi akademik yang dilaksanakan oleh pengawas dan Kepala sekolah terhadap kinerja guru sosiologi mampu memberikan kontribusi lebih dalam memaksimalkan kegiatan kesupervisian. Kepala sekolah secara terbuka dapat bekerjasama dengan pengawas sehingga lebih mampu melaksanakan perannya dalam menggerakkan, mengkoordinasikan, dan memberikan pengaruh positif terhadap guru sosiologi untuk meningkatkan kinerjanya, sehingga pada tahap lanjut dapat mempengaruhi kualitas pembelajaran dalam rangka meningkatkan mutu pendidikan.

\section{Daftar Pustaka}

Ansori, A., Supriyanto, A., \& Burhanuddin, B. (2016). Pelaksanaan Supervisi Klinis Dalam Meningkatkan Kinerja Guru Sekolah Dasar. Jurnal Pendidikan: Teori, Penelitian, dan Pengembangan, 1(12), 2321-2326.

Firmansyah, E. (2020). Pengaruh Tingkat Kecerdasan Emosional Siswa Terhadap Hasil Belajar SFirmansyah, E. (2020). Pengaruh Tingkat Kecerdasan Emosional Siswa Terhadap Hasil Belajar Siswa Pada Mata Pelajaran IPA. Ilmu Sosial Dan Pendidikan, 4(3), 3.iswa Pada Mata Pelajaran IPA. Ilmu Sosial dan Pendidikan, 4(3), 3-5.

Marismania, N. (2020). Meningkatkan Kompetensi Guru dalam Mengajar Melalui Kegiatan Suoervisi Akademik Dengan Teknik Individu di SD Binaan Kecematan Situbondo Kabupaten Situbondo Tahun Pelajaran 2019/2020. Edukasi Gemilang, 5(3), 64-71.

Mayang, H. R. (2020). Peran Pengawas Pendidikan Dalam Peningkatan Mutu Pendidikan (Studi Kasus di Raudhatul Athfal Kota Bandung Provinsi Jawa Barat). Menata, 3(2), 1-10.

Nurindarwati, R. (2020). Penerapan Supervisi Akademik Pengawas Upaya Peningkatan Kemampuan Guru Dalam Penyusunan Administrasi Pembelajaran. Al-Munqidz: Jurnal Kajian Keislaman, 8(1), 14-34.

Sagala, S. (2011). Kemampuan Profesional Guru dan Tenaga Kependidikan. Alfabeta: Bandung.

Sugiyono, S. (2006). Metode Penelitian Kualitatif, Kualitatif dan R\&D. Bandung: Alfabeta.

Suhardan, D. (2007). Efektivitas Pengawasan Profesional dalam Meningkatkan Mutu Pembelajaran pada Era Otonomi Daerah. Educationist, 1(1), 57-64.

Sukmadinata, S \& Nana, S. (2007). Metode Penelitian Pendidikan. PT. Remaja Rosdakarya.

Syahruddin, S., Djasmi, S., \& Suntoro, I. (2015). Peran Pengawas dalam Implementasi Kurikulum 2013 pada SMA Negeri di Kabupaten Tanggamus. Jurnal Manajemen Mutu Pendidikan, 3(1), 1-10.

Upe, A. (2010). Tradisi Aliran dalam Sosiologi dari Filosofi Positivistik ke Post Positivistik. Bandung: Alfabeta

Yunathan, R. (2020). Meningkatkan Kinerja Guru dalam Pembelajaran Melalui Supervisi Akademik Metode Direktif di SDN Muara Jolol 1 Tahun Ajaran 2018/2019. Mitra Pendidikan, 4(8), 538-553. 